Int. J. Curr. Res. Med. Sci. (2017). 3(5): 61-70

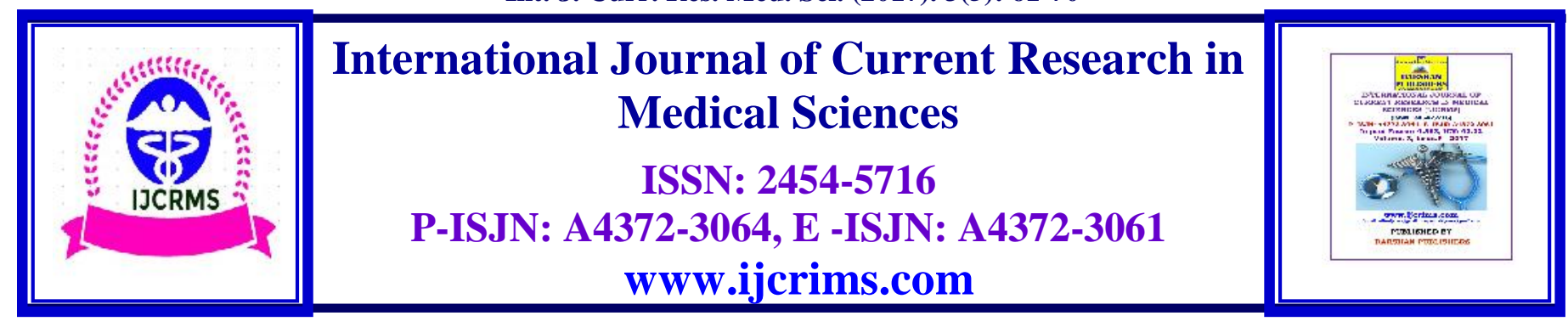

\title{
Observation of Apoptosis in Calves Experimentally Infected With Pasteurella multocida Serotype B:2
}

\author{
Amna E.M. ${ }^{1}$, Hanan Moawia Ibrahim ${ }^{2}$ and Jasni S. $^{3}$ \\ ${ }^{1}$ Faculty of Pharmacy. Northern Border University, Saudi Arabia \\ ${ }^{2}$ Central Lab. Ministry of Higher Education and Scientific Research. Sudan \\ ${ }^{3}$ Faculty of Veterinary Medicine, Universiti Putra Malaysia, Malaysia. \\ Corresponding author: Dr. Amna Elamin \\ Faculty of Pharmacy. Northern Border University, Saudi Arabia \\ E-mail: amnamogwari@gmail.com
}

Hp:00966533506522

\begin{abstract}
Calves infected intranasally with $3.0 \times 10^{10}$ Pasteurella multocida serotype B:2 following dexamethasone treatment died acutely between 24 to 48 hours. All infected calves showed severe swelling of epithelial cells of the nasal mucosa, trachea and lung. Some endothelial cells of the capillary of nasal mucosa, trachea and lung showed condensation of the cytoplasm, chromatin margination, and vesicular surface. Bacteria were found in close contact with endothelial cell membrane. Some of the neutrophils were undergoing apoptosis with perinuclear chromatin aggregation and cytoplasmic vacuolization. Detached apoptotic endothelial cells were also seen in the lumen of the blood vessels. These findings suggest that apoptosis in infected neutrophils and endothelial cells may contribute to the pathogenesis of haemorrhagic septicaemia.
\end{abstract}

Keywords: Pasteurella multocida B:2, TEM observation, Endothélial cell, Apoptosis

\section{Introduction}

Hemorrhagic septicemia $(\mathrm{H} \mathrm{S})$ is caused by Pasteurella multocida $\mathrm{B}: 2$ a is highly fatal disease in cattle and water buffalo in Asia resulting in septicaemia where organs of affected animals are haemorrhagic (Carter, 1998; De Alwis, 1995; Shewen and Rice-Conlon, 1993). Pasteurella multocida $\mathrm{B}: 2$ is a facultative bacteria and this group of bacteria can survive both in extracellular and intracellular environment of host cell (Kilian and Fredericksen, 1981) the microorganisim has been observed extraceullarly and intracellularly in rabbits infected with $P$. multocida serotype A (AlHaddawi, 1999). Their intracellular residence within vacuoles inside the cytoplasm of the nasal mucosal epithelium and type 1 pneumocyte of infected rabbits have been observed to cause pulmonary injuries in rabbits (Al-Haddawi, 1999). It is possible that the haemorrhages seen in HS are due to injuries associated with the facultative parasitism of $P$. multocida $\mathrm{B}: 2$ which is as yet 
revealed. The pathogenesis of haemorrhage in some haemorrhagic diseases such as leptospirosis caused by L. icterohaemnorrhagiae (Higgins and Cousineau, 1977), Haemophilus septicemia in pigs caused by Haemophilus organism (Thomson and Louise, 1963) and bovine pulmonary pasteurellosis caused by $P$. hemolytica have been revealed (Breider et al., 1988). Pathogenesis of leptospirosis has been attributed to thrombocytopenia, capillary wall damage and pathological alteration of blood coagulation and capillary plugging caused by an antigen-antibody interaction (Thomson and Louise, 1963). $P$. haemolytica is believed to cause direct endothelial damage and also initiate interlukin-1 and tumor necrosis factor production by the alveolar macrophage, leading to severe vascular thrombosis, hemorrhage, edema and tissue necrosis (Breider et al., 1990).

Other microorganisms such as Haemophilus somnus cause respiratory disease and vasculitis in cattle and induced apoptosis in bovine endothelial cells (Gogolewski et al., 1987; Style et al., 2001). Disruption of vessel endothelium by endothelial cell apoptosis can contribute to the pathogenesis of vascular leakage in many diseases such as, dengue (Lin et al., 2002) and anthrax (Kirby, 2004). It is possible that the endothelial cells are the early cellular target of $P$. multocida in causing haemorrhages. Vascular damage can be induced by direct infection of the vascular tissue by $P$. multocida triggered by cytolysis of endothelial cells and factors secreted from infected monocytes/macrophages or by apoptosis. This study investigates the possible endothelial cells pathology causing hemorrhage seen in haemorrhagic septicaemia in cattle.

\section{Materials and Methods}

Seven and 14 weeks old experimental calves and two control calves were used in this study. They were housed in individual pens, fed daily with pellet, cut grasses and water ad libitum. Nasal swabs were taken from the animals prior to their respective treatments. To induce stress in the experimental calves, $8 \mathrm{ml}$ of dexamethasone (Alfasan, WOERDEN-HOLLAND) were intravenously administered daily into each animal for 5 consecutive days. After 24 hours, they were inoculated intranasally with $3.0 \times 10^{10}$ Pasteurella multocida serotype B:2 in $5 \mathrm{ml}$ of phosphate buffered saline (PBS). Two control calves were inoculated intranasally with PBS.

All infected calves died between 24 to 48 hours after infection. For electron microscopic examination, one $\mathrm{mm}^{3}$ pieces of tissues of nasal mucosa, trachea and lung were fixed in $4 \%$ glutaraldehyde in $0.1 \mathrm{M}$ sodium cacodylate buffer (PH 7.4) at $4^{\circ} \mathrm{C}$ overnight. The samples were then washed at 10 minutes intervals with two changes of cacodylate buffer alone and processed for transmission electron microscopy (TEM) using standard methods. Briefly, the samples were fixed with $4 \%$ glutaraldehyde. The samples were then washed 3 times in $0.1 \mathrm{M}$ sodium cocdylate buffer for 10 minutes each and post fixed for 2 hours with $1 \%$ osmium tetroxide (OsO4). Fixed samples were rinsed, dehydrated in a graded acetone the samples were embedded in resins, cut into ultrathin sections on Ultracut E (Reichert-Jung. Austria) microtome and mounted on 200-meshcopper grids. The sections were stained with uranyl acetate and lead citrate and examined using transmission electron microscope (Hitachi 7100, Japan).

\section{Results}

\section{Nasal Mucosa and Trachea}

All infected calves had severely swollen epithelial cells. Some endothelial cells of the capillary showed condensation of the cytoplasm, chromatin margination and vesicular surface. Bacteria were found in close contact with endothelial cell membrane. In the lumen of the blood vessels, there were presence of neutrophils, monocyte, macrophages and aggregation of platelets. Some of the neutrophils were undergoing apoptosis with perinuclear chromatin aggregation and cytoplasmic vacuolization. Detached apoptotic cells are also seen in the lumen of the blood vessel (Figures 1 to 3 ). 
Int. J. Curr. Res. Med. Sci. (2017). 3(5): 61-70

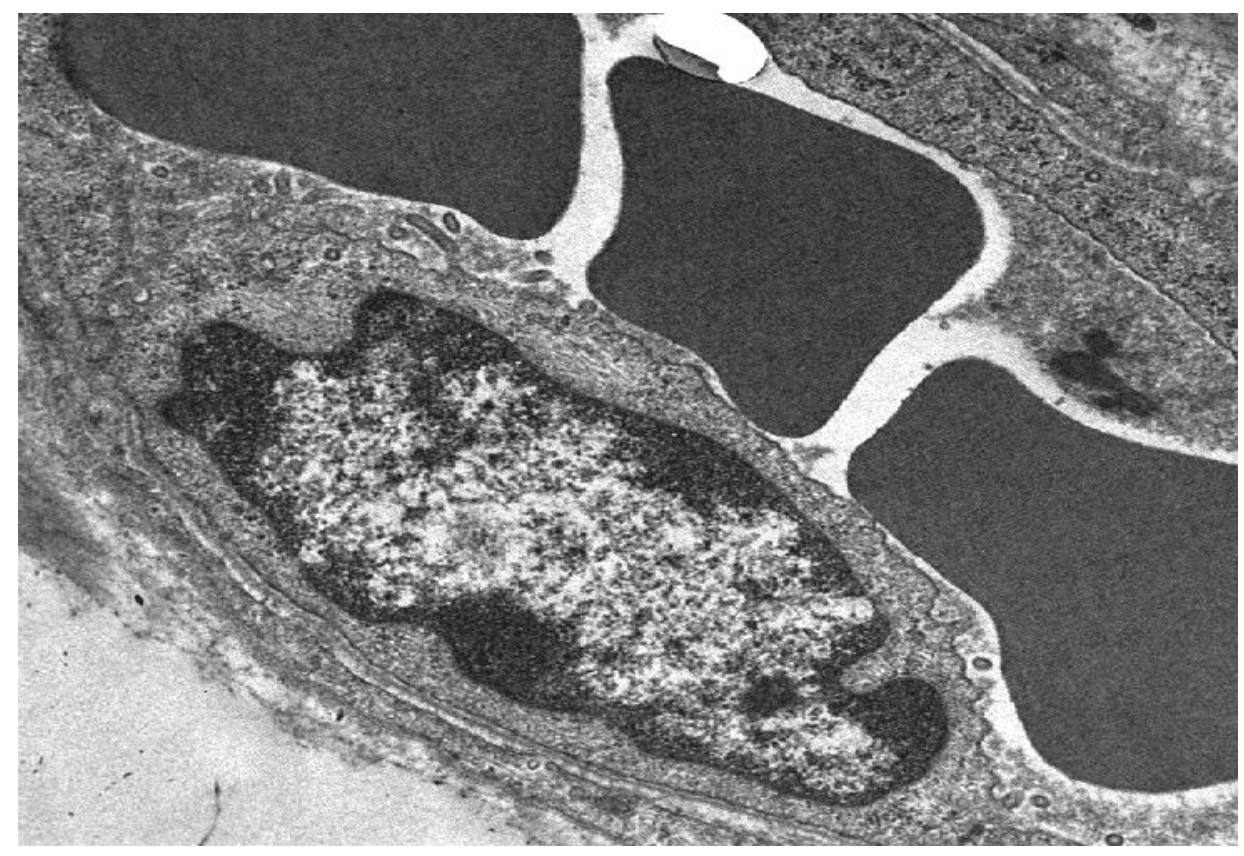

Figure 1: Electron micrograph of the nasal mucosa of calf no 3 that died 36 hours p.i. Note erythrocytes are adhered to the membrane of apoptotic endothelial cell. Lead citrate \& uranyl acetate. TEM X 1356.

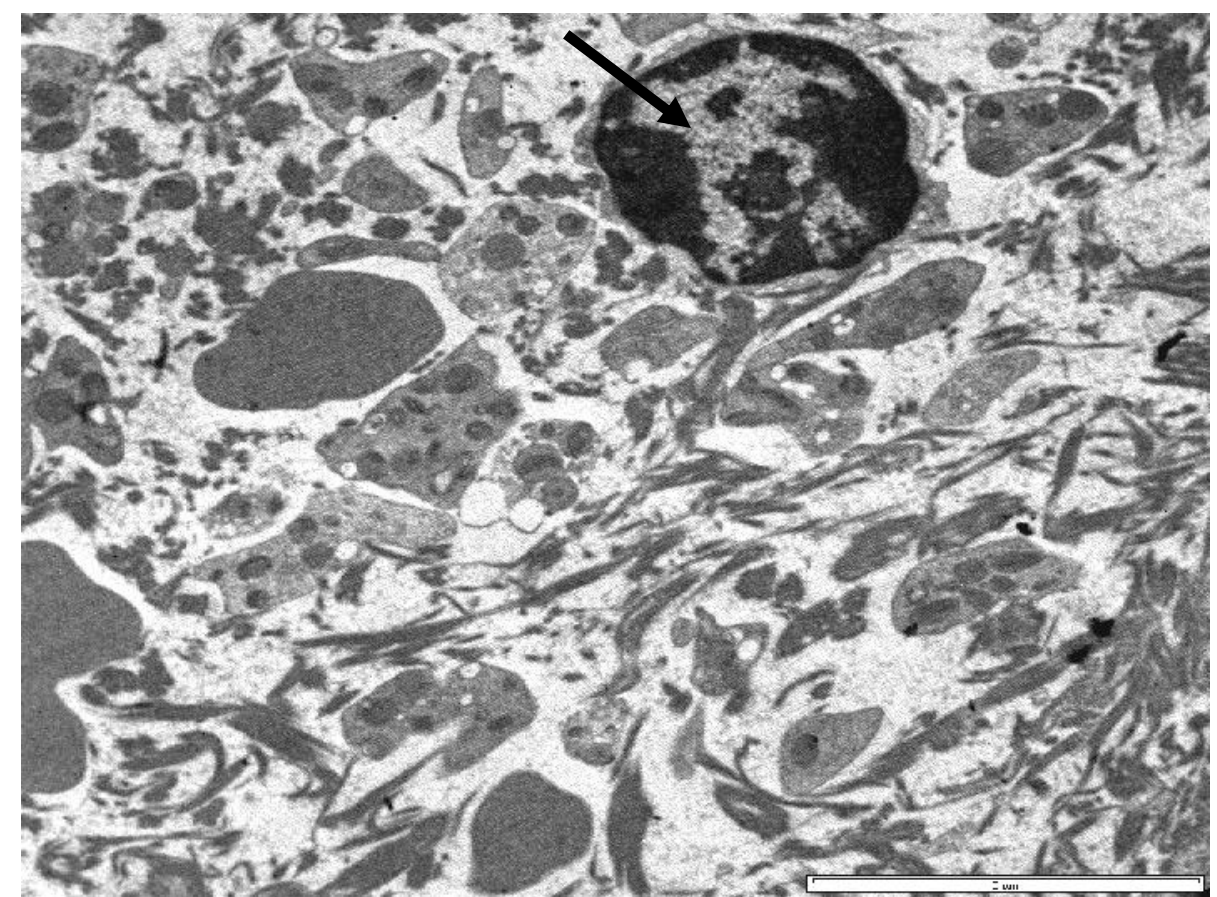

Figure 2: Electron micrograph of the nasal mucosa of calf no 3 that died 36 hours p.i. Note the presence of platelets and deposition fibrin in the lumen of the blood vessel (thrombus). Detached apoptotic cell (arrow) is also seen in the lumen of the blood vessel. Lead citrate \& uranyl acetate. TEM X 1087. 
Int. J. Curr. Res. Med. Sci. (2017). 3(5): 61-70

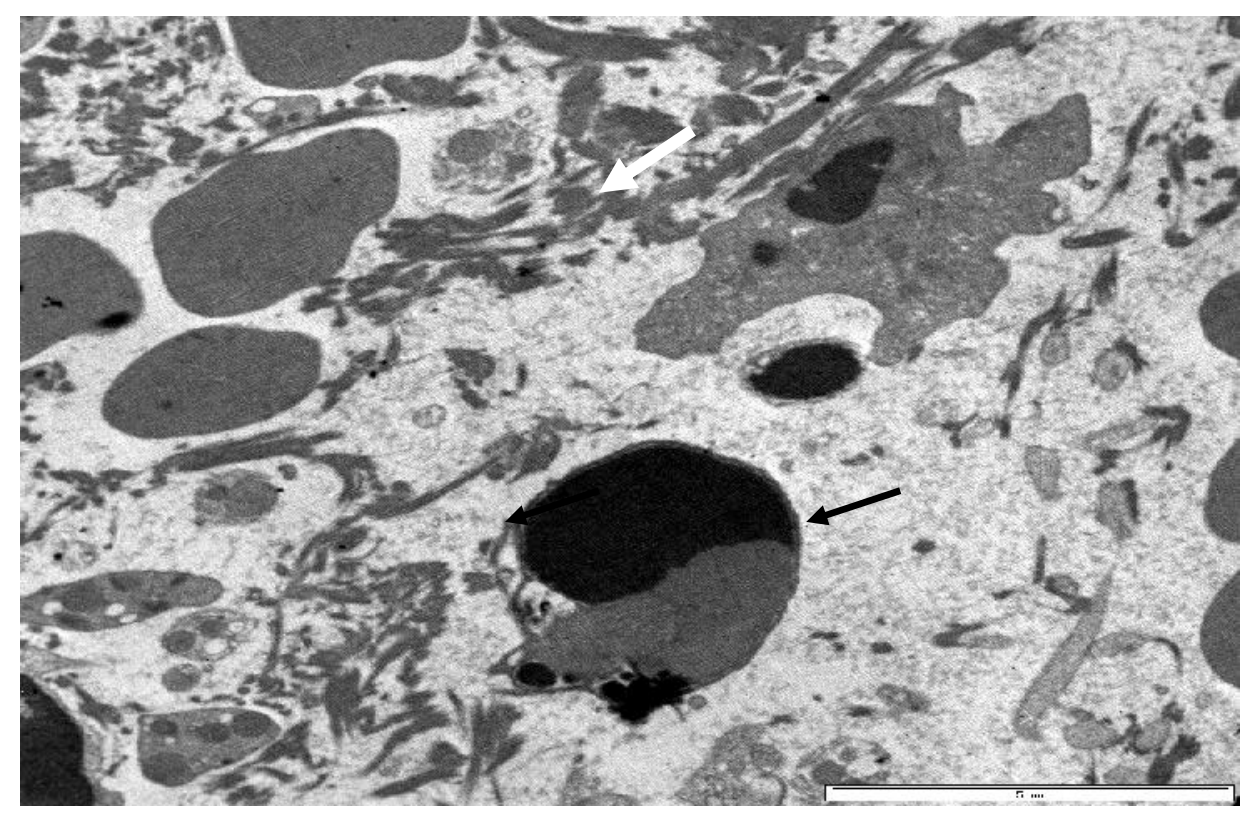

Figure 3: Electron micrograph of the nasal mucosa of calf no 3 that died 36 hours p.i. Note the presence of apoptotic neutrophil (arrows). Lead citrate \& uranyl acetate. TEM X 1087.

\section{Lung}

The ultrastructural changes observed in the lungs of all infected calves were thickening of the alveolar walls due to congestion of alveolar capillaries, swelling of capillary endothelium and increased number of granular pneumocytes. Some of the shrunken endothelial cells were electron dense and were vacuolated. These cells had condensed chromatin and some had apoptotic bodies. Some apoptotic endothelial cells with fragmented nucleus were evident. Some apoptotic pneumocytes appeared to have condensed chromatin around the periphery of the nucleus. The apoptotic pneumocyte protruded into the alveolar lumina. There were intracytoplasmic, non- membrane bound bacteria in the endothelial cells (Figures 4 to 9 ).

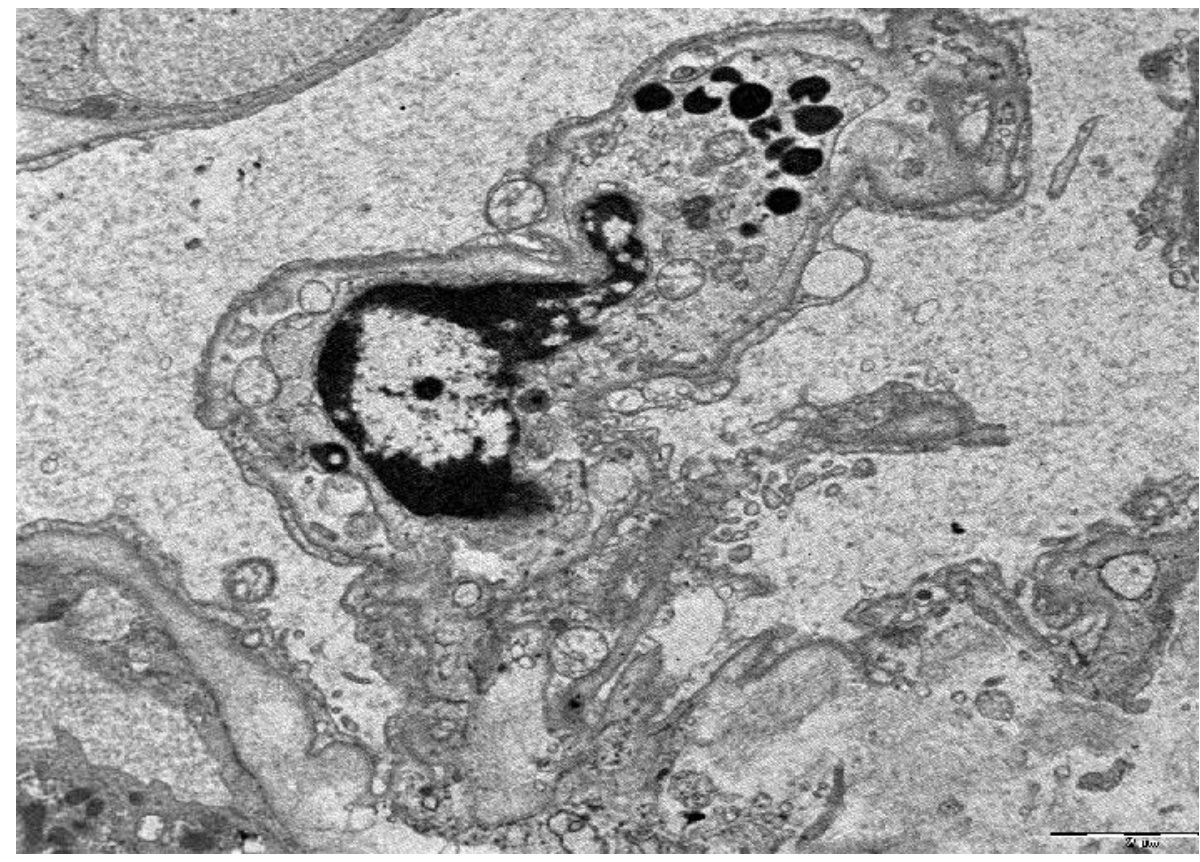

Figure 4: Electron micrograph of the lung of calf no 3 that died 36 hours p.i. Note the apoptotic pneumocyte appeared to have condensed chromatin around the periphery of the nucleus. The apoptotic pneumocyte protrudes into the alveolar lumina. Lead citrate \& uranyl acetate. TEM X 1537. 
Int. J. Curr. Res. Med. Sci. (2017). 3(5): 61-70

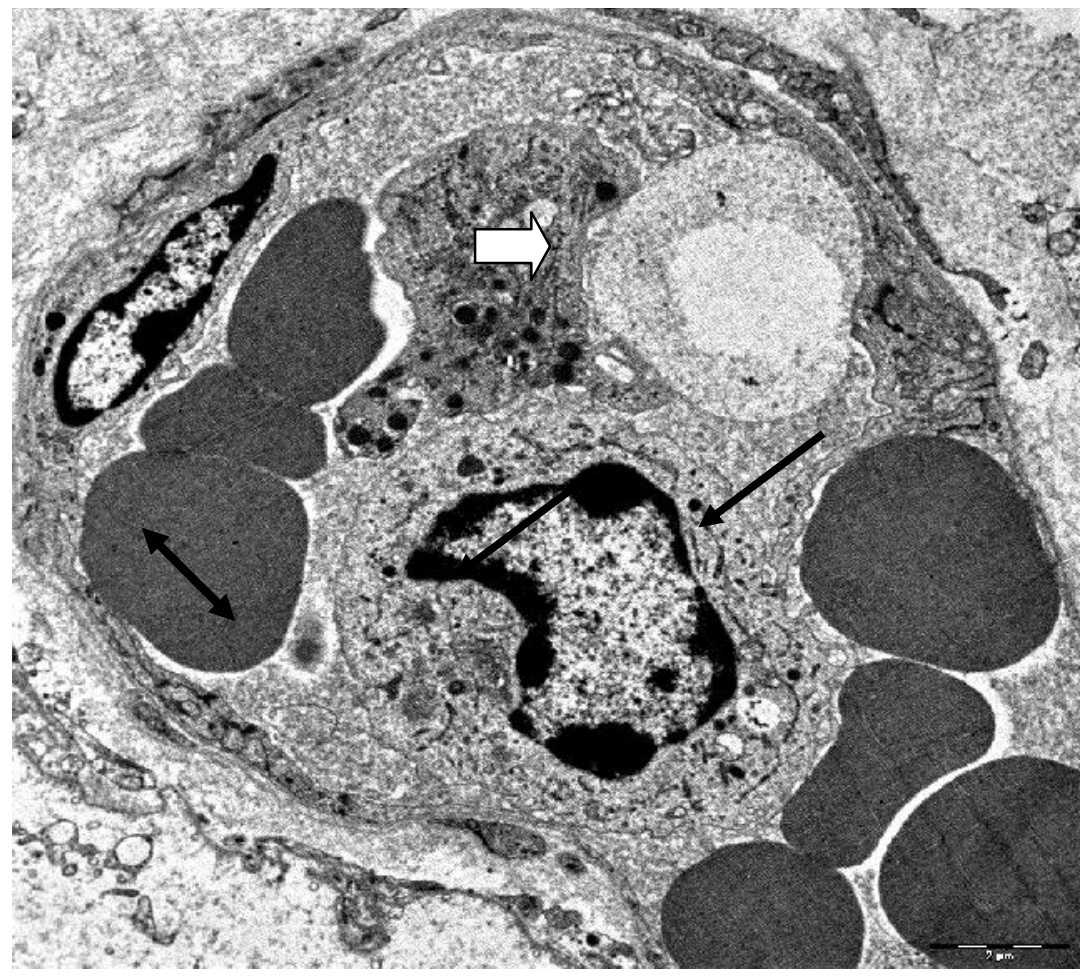

Figure 5: Electron micrograph of the lung of calf no 3 that died 36 hours p.i. Note platelet (white arrow) with pseudopods is attached to the adjacent necrotic cell. Erythrocytes (double arrow) is seen binded to degenerate endothelial cell. Markedly swollen endothelial cell (long arrow) with chromatin condensation around the periphery of the nucleus (apoptosis) is protruded into the lumen of the blood vessel. Lead citrate \& uranyl acetate. TEM X 1356.

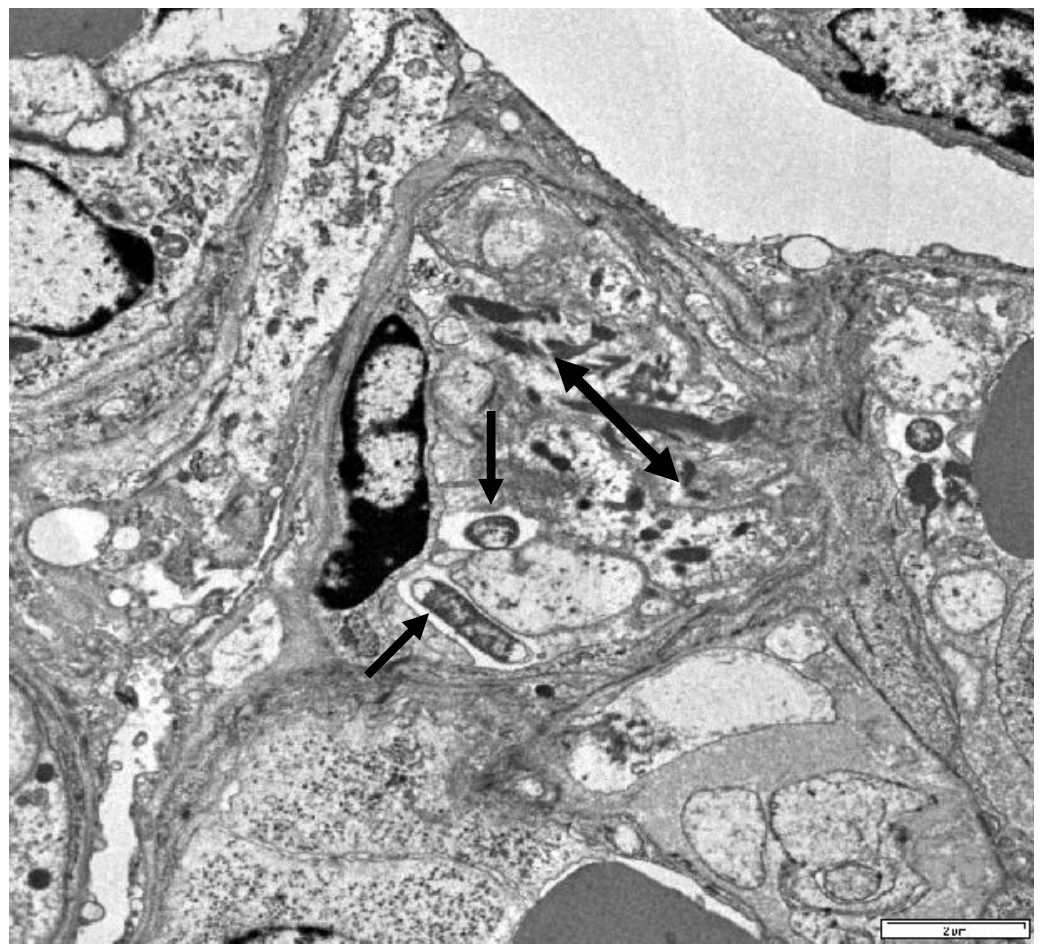

Figure 6: Electron micrograph of the lung of calf no 3 that died 36 hours p.i. Note electron lucent bacteria (arrows) are seen in the capillary lumen adjacent to swollen and apoptotic endothelial cell. The capillary lumen is occluded with fibrin (double arrow) and cell remnants. Lead citrate \& uranyl acetate. TEM X 1840. 


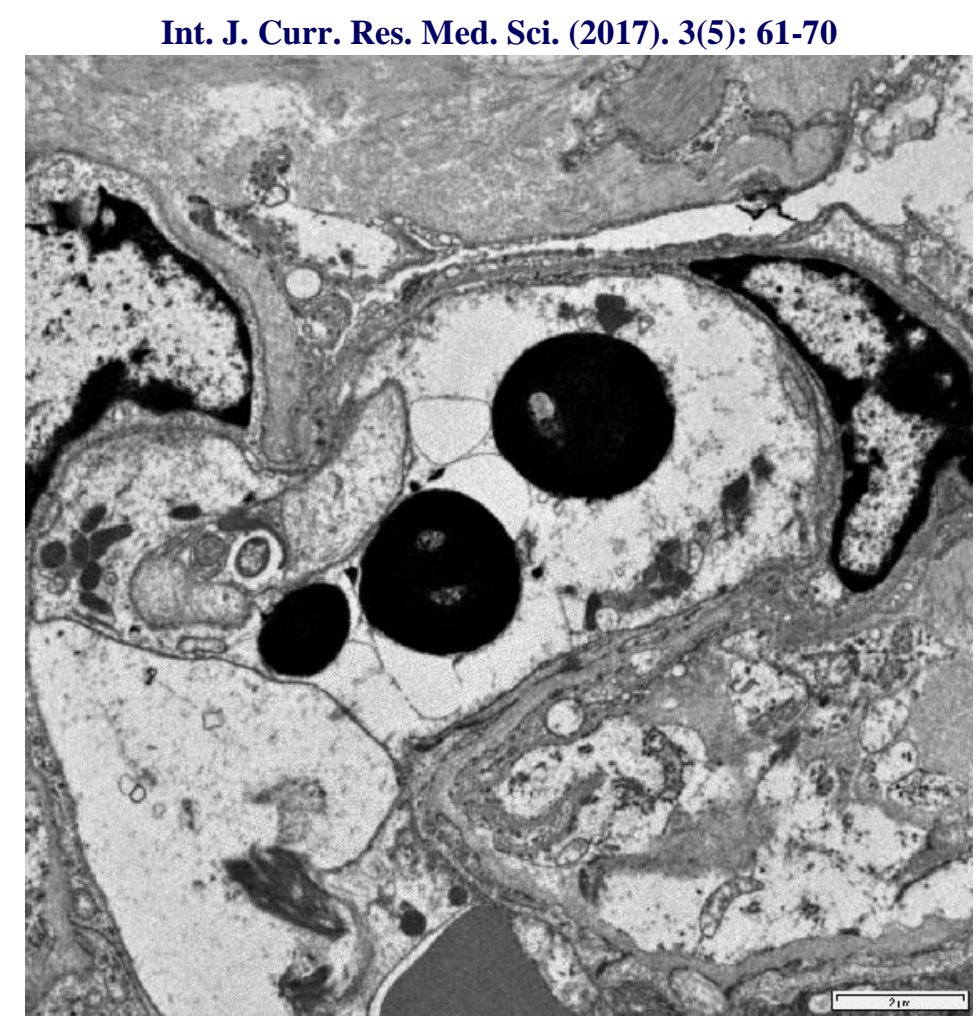

Figure 7: Electron micrograph of the lung of calf no 3 that died 36 hours p.i. Note the endothelial cell is undergoing apoptosis. Apoptotic bodies are evident (big arrow). A free intracytoplasmic bacterium is seen in the endothelial cell (small arrow). Lead citrate \& uranyl acetate. TEM X 1356.

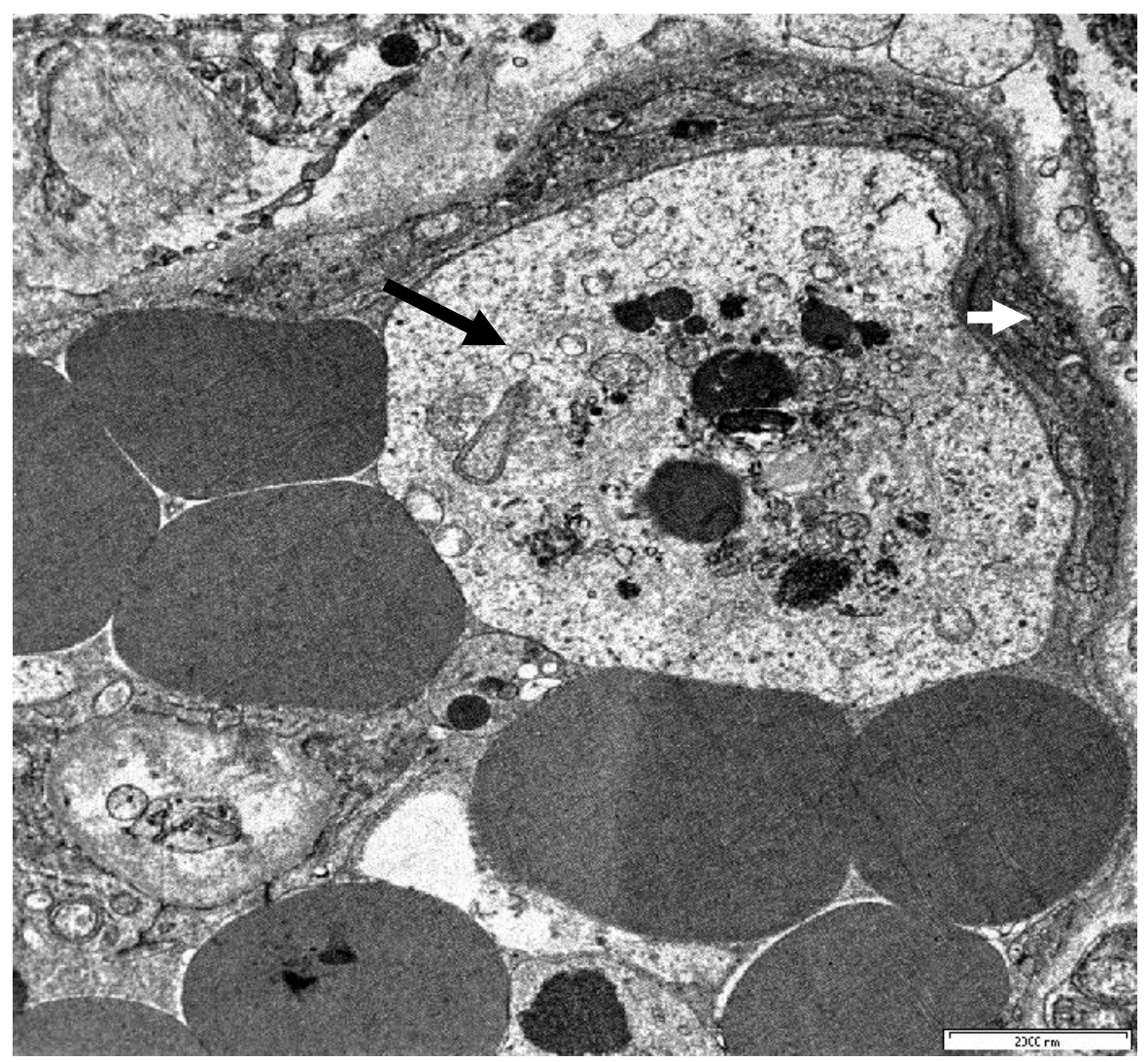

Figure 8: Electron micrograph of the lung of calf no 3 that died 36 hours p.i. Note an apoptotic endothelial cell (white arrow) with fragmented nucleus. Deposition of fibrin and protein granules (short arrow) in the capillary basement membrane are also evident. Lead citrate \& uranyl acetate. TEM X 1667. 
Int. J. Curr. Res. Med. Sci. (2017). 3(5): 61-70

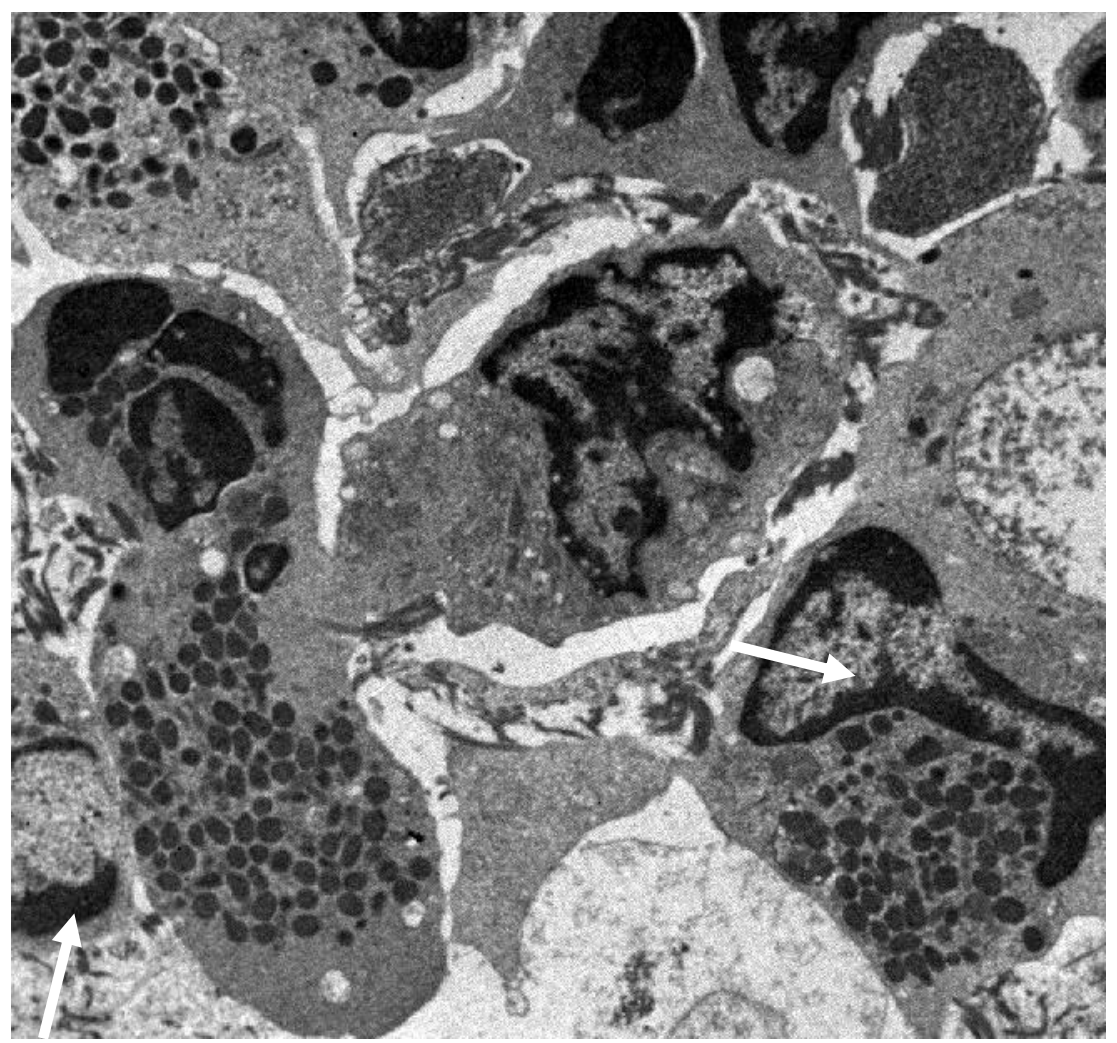

Figure 9: Electron micrograph of the lung of calf no 3 that died 36 hours p.i.. Note apoptotic neutrophils (big arrows) with condensation of chromatin. Lead citrate \& uranyl acetate. TEM X 1356.

\section{Discussion}

Morphological changes in endothelial cells that are characteristic of an apoptotic process (Susin et al., 1999; Daugas et al., 2000) led us to suggest that $P$. multocida damages the endothelial cells via apoptosis. To our knowledge, there has been no report on apoptosis of endothelial cells induced by $P$. multocida. These findings suggest that apoptosis may be occurring and it could explain, in part apoptosis contribute to the endothelial damage and vasculitis that are observed in this study. Also TEM observations revealed $P$. multocida induced apoptosis in infected neutrophils. This shows that the inflammatory response in the host is unable to clear the bacteria and the infection is allowed to proceed, resulting in HS. Although there have been no reports characterizing the interaction of $P$. multocida and endothelial cells, these findings suggest that apoptosis might be linked to $P$. multocida endotoxin. Sylte et al. (2001) has demonstrated that $H$. somus induced endothelial cell apoptosis in vitro. These authors also reported that exposure of endothelial cells to $H$. somus lipooligosaccharide (LOS) may be a key virulence factor capable of mediating endothelial cell apoptosis and ultimately vasculitis. Several bacterial pathogens such as Staphylococcus aureus (Menzies and Kouteva, 1998), Rickettsia rickettsii (Clifton et al., 1998), Orienntia tsutsugamushi (Kee et al., 1999, Kim et al., 1999), have been shown to induce endothelial cells apoptosis in vitro. Chen and Zychlinsky (1994) noted that some bacteria produced toxins to kill host cell by apoptosis. These authors also reported that apoptosis induced by bacteria appears to contribute to infectious diseases. Zychlinsky and Sansonetti (1997) demonstrated that infection of cells by some pathogenic bacteria triggers host cell apoptosis. These authors observed that bacteria-induced apoptosis appears to promote an inflammatory response that causes tissue damage and further bacterial colonization. Host cell killing would benefit the bacteria by the induction of apoptosis of epithelial cells, thus allowing sloughing off of the infected epithelium. This would serve as a vehicle for clearance and bacterial dissemination as suggested by Pier et al. (1996). Bacteria that produce exotoxins, like 
Corynebacterium diphtheriae and Pseudomonas spp (Kochi, and Collier 1993), Actinobacillus actinomycetemcomitans (Taichman et al., 1980, Kato et al., 1995) and Bacillus anthracis (Hanna et al., 1993), may benefit from killing macrophages before they ingest and destroy the bacteria. Bordetella pertussis induced apoptosis by expressing adenylate cyclase-hemolysin toxin early during the course of colonization to allow the bacteria to survive in the initial stages of the infection. After the bacteria have successfully colonized the tissue, Bordetella ceases to produce this toxin (Khelef et al 1993; Khelef and Guiso, 1995). Pseudomonas aeruginosa can induce apoptosis by producing exotoxin A (Kochi, and Collier 1993). Ultrastructural findings in this study showed acute endothelial cell swelling leading to damage and most of the cell that becomes apoptotic are detached. This study supports the hypothesis that endotoxin in the lipopolysaccharide complex in the outer wall of the gram-negative bacteria causes severe injury to endothelium of pulmonary capillaries (Hirata et al., 1980). Several bacterial pathogens such as Haemophilus somnus (Style et al., 2001), Rickettsia rickettsii (Clifton et al., 1998), Staphylococcus aureus (Menzies and Kourteva, 1998) and others have been shown to induce endothelial cell apoptosis in vitro. Apoptosis may contribute to the pathogenesis of the diseases in vivo by impairing immune surveillance and promoting bacterial survival. Thomson and Little (1981) compare the adherence of $H$. somus, E coli and S. enterica serovar typhimurium organisms to vascular endothelial cells. Although these findings suggest induction of apoptosis, the mechanism of cellular cytotoxicity was not addressed. However, the authors suggested that it might link to $H$. somus endotoxin. Whereas Style et al. (2001) suggested that the morphological changes were induced by tumor necrosis factor- $\alpha$, $H$. somus, or a combination thereof. In recent study, Style et al. (2006) concluded that TNF- $\alpha$ enhanced lipooligosaccharide (LOS)-induced apoptosis of bovine endothelial cells, but only in the presence of the protein synthesis inhibitor cycloheximidine. Blocking protein synthesis also enhanced LOS-induced apoptosis. LOS appears to induce endogenous release of TNF- $\alpha$, which plays a role in enhancing LOS-induced apoptosis. The most obvious scenario of this study suggested that induction of apoptosis in professional phagocytes, like neutrophils and macrophages would be beneficial since these are the most lethal cells for bacterium. This impairment of phagocytosis results in vascular damage, thrombosis and failure of bacterial clearance. Another important finding was that $P$. multocida can activate apoptosis to attack and kill endothelial cells that contribute to the pathogenesis of hemorrhagic septicemia. On the basis of these findings one can consider endothelial apoptosis may contribute to the vascular pathology observed during this study. Thus, endothelial cell apoptosis may be related to the disruption of endothelial barrier and then lead to vascular leakage. This may therefore contribute to the devastating hemorrhagic complication of hemorrhagic septicemia. It has been reported that the endothelial apoptosis may lead to the transient leakage syndrome in dengue vasculopathy (Lin et al 2002). Anthrax lethal toxin can induce human endothelial cell apoptosis (Kirby, 2004). This experimental observation suggested that a direct insult to the host vasculature may contribute to hemorrhage during systemic anthrax.

Further studies are important to study the mechanism of apoptosis in endothelial cells triggered by $P$. multocida serotype B:2.

\section{Conclusion}

Pasteurella multocida serotype B:2 infected calves showed severe swelling of epithelial cells of the nasal mucosa, trachea and lung. Some endothelial cells of the capillary of nasal mucosa, trachea and lung showed condensation of the cytoplasm, chromatin margination, and vesicular surface. Bacteria were found in close contact with endothelial cell membrane. Some of the neutrophils were undergoing apoptosis with perinuclear chromatin aggregation and cytoplasmic vacuolization. Detached apoptotic endothelial cells were also seen in the lumen of the blood vessels. 


\section{References}

Al-Haddawi, M. H. (1999). Pathogenicity of Pasteurella multocida Serotypes A:3, D:1 and D:3 in Rabbits. PhD. Thesis, Universiti Putra Malysia.

Carter, G.R. 1998. "Hemorrhagic Septicemia" In Foreign Animal Diseases. pp. 446- 456. Richmond, VA: United States Animal Health Association.

Chen, Y. and Zychlinsky, A. 1994. Apoptosis induced by bacterial pathogens. Microbial Pathogenesis 17:203-212.

Clifton, D.R., Goss, R.A., Sahni, S.K., Van Antwerp, D. Baggs, R.B., Marder, V.J., Silverman, D.J. and Sporn, L.A. 1998. NFkappa B-dependent inhibition of apoptosis is essential for host cell survival during Rickettsia rickettsii infection. Proceedings of the National Academy of Sciences USA. 95:4646-4651.

Daugas, E., Susin, S.A., Zamzami, N., Ferri, K.F., Irinopoulou, T., Larochette, N., Prevost, M.C., Leber, B., Andrews, D., Penninger, J. and Kroemer, G. (2000). Mitochondrio-nuclear translocation of AIF in apoptosis and necrosis. FASEB. J. 14:729-739.

De Alwis, M.C.L. 1995. Hemorrhagic septicemia (Pasteurella multocida serotype B:2 and E:2 infection) in cattle and buffaloes, pp: 9-24. In Donachie, W., Lainson, F. A. and Hodgson, J.C. (ed.), Haemophilus, Actinobacillus and Pasteurella. Plenum Press, London, United Kingdom.

Hanna, P.C., Acosta, D. and Collier, R.J. 1993. The role of macrophages in anthrax. Proceedings of the National Academy of Sciences USA. 90: 10198-10201.

Hirata, K., Kaneko, A., Ogawa, K., Hayasaka, H. and Onoe, T. 1980. Effect of endotoxin on rat liver. Analysis of acid phosphatase isozymes in the liver of normal and endotoxin-treated rats. Laboratory Investigation 43:165-171.

Gogolewski, R.P., Leathers, C.W., Liggitt, H.D. and Corbeil, L.B. (1987). Experimental Haemophilus somnus pneumonia in calves and immunoperoxidase localization of bacteria. Vet. Pathol. 24:250-256.
Kato, S., Muro, M., Akifusa, S., Hanada, N., Semba, I., Fujii, T., Kowashi, Y. and Nishihara, T. 1995. Evidence for apoptosis of murine macrophages by Actinobacillus actinomycetemcomitans infection. Infection and Immunity 63: 3914-3919.

Kee, S.H., Cho, K.A., Kim, M.K., Lim, B.U., Chang, W.H. and Kang, J.S. 1999. Disassemply of focal adhesions during apoptosis of endothelial cell line ECV304 fected with Orientia tsutsugamushi. Microbial Pathogenesis 27: 265-271.

Khelef, N., Danve, B., Quentin-Millet, M. J. and Guiso, N. 1993. Bordetella pertussis and Bordetella parapertussis: two immunologically distinct species. Infection and Immunity 61: 486-490.

Khelef, N. and Guiso, N. 1995. Induction of macrophage apoptosis by Bordetella pertussis adenylate cyclase-hemolysin. FEMS Microbiology Letters 134: 27-32.

Kilian, M. and Fredericksen, W. (1981). Identification Tables for the HaemophilusPasteurella-Actinobacillus group. In: Kilian, M., Frederiksen, W. and Biberstein, E. L. (eds) Haemophilus, Pasteurella and Actinobacillus, Academic Press, London. Pp. 281-290.

Kim, M.K., Kee, S.H., Cho, K.A., Chung, M.H., Lim, B.U., Chang, W.H. and Kang, J.S. 1999. Apoptosis of endothelial cell line ECV304 persistently infected with Orientia tsutsugamushi. Microbiology and Immunology 43: 751-757.

Kirby, E.J. 2004. Anthrax Lethal Toxin Induces Human Endothelial Cell Apoptosis. Infection and Immunity 72: 430-439.

Kochi, S.K. and Collier, R.J. 1993. DNA fragmentation and cytolysis in U937 cells treated with diphtheria toxin or other inhibitors of protein synthesis. Experimental Cell Research 208: 296-302.

Lin, C., Lei, H., Shiau, A., Liu, H., Yeh, T., Chen, S., Liu, C., Chiu, S. and Lin2, Y. 2002. Endothelial Cell Apoptosis Induced by Antibodies Against Dengue Virus Nonstructural Protein 1 Via Production of Nitric Oxide1. Journal of Immunology 169: 657-664. 
Menzies, B.E. and Kourteva, I. 1998. Internalization of Staphylococcus aureus by endothelial cells induces apoptosis. Infection and Immunity 66: 5994-5998.

Pier, G., Grout, M., Zaidi, T., Olsen, J., Johnson, L.,Yankaskas, J. and Goldberg, J. (1996). Role of mutant CFTR in hypersusceptibility of cystic fibrosis patients to lung infections. Science 271:64-67.

Shewen, P.E. and Rice Conlon, J.A. 1993. Pasteurella, p. 216-225. In C. L. Gyles and C. O. Thoen (ed.), Pathogenesis of bacterial infections in animals, 2nd ed. Iowa State University Press, Ames. I A.

Susin, S.A., Lorenzo, H.K., Zamzami, N., Marzo, I., Snow, B.E., Brothers, G.M., Mangion, J., Jacotot, E., Costantini, G. and Loeffler, P.M. (1999). Molecular characterization of mitochondrial apoptosis-inducing factor. Nature. 397:441-446.

Sylte, M.J., Corbeil, L.B., Inzana, T.J., Czuprynski, C.J. 2001 Haemophilus somnus induces apoptosis in bovine endothelial cells in vitro. Infection and Immunity 69: 1650-1660.

Sylte, M.J., Kuckleburg, C.J., Leite, F.P., Inzana, T.J. and Czuprynski, C.J. 2006. Tumor necrosis factor-alpha enhances Haemophilus sommus lipooligosaccharide-induced apoptosis of bovine endothelial cells. Veterinary Immunology and Immunopathology 110: 303309.

Taichman, N., Dean, R. and Sanderson, C. 1980. Biochemical and morphological characterization of the killing of human monocytes by a leukotoxin derived from Actinobacillus actinomycetemcomitans. Infect. Immun. 28: 258-268.

Thompson, K.G. and Little, P.B. 1981. Effect of Haemophilus somnus on bovine endothelial cell in organ culture. American Journal of Veterinary Research 42: 748-754.

Zychlinsky, A. and Sansonetti P.J. 1997. Apoptosis as a proinflammatory event: what can we learn from bacterial-induced cell death. Trends in Microbiology 5: 201-204.

\begin{tabular}{|c|l|}
\hline \multicolumn{2}{|c|}{ Access this Article in Online } \\
\hline 品 & Website: \\
\hline & www.ijcrims.com \\
\cline { 2 - 2 } & Subject: \\
& Veterinary \\
\hline Quick Response Code & Medicine \\
\hline
\end{tabular}

How to cite this article:

Amna E.M., Hanan Moawia Ibrahim and Jasni S. (2017). Observation of Apoptosis in Calves Experimentally Infected With Pasteurella multocida Serotype B:2. Int. J. Curr. Res. Med. Sci. 3(5): 6170.

DOI: http://dx.doi.org/10.22192/ijcrms.2017.03.05.010 